\title{
Academic Performance Management Policy for Changing Roles of Universities in Innovation Systems
}

\author{
Sercan Ozcan, M. Sadettin Ozyazici and M. Baris Ozerdem \\ Faculty of Engineering and Natural Sciences, Bahcesehir University, Istanbul, Turkey \\ E-mail: sercan.ozcan@eng.bau.edu.tr
}

\begin{abstract}
The purpose of this study is to establish a new performance measurement method for academic actors for their changing roles in innovation systems. The widely accepted triple helix and systems of innovation models show changing and overlapping roles of academic, industrial and governmental actors. In previous innovation systems, universities were not focused on applied research and technology transfer as much as they are now. Current literature shows a changing role of universities and importance of their involvement in innovation systems.

Although academic organizations' roles have changed in innovation systems, academic performance measurement systems (APMS) are not adapted to examine innovation related performance factors. Many APMS focus on key performance indicators (KPIs) such as; publications, research projects and patents. However, the new APMS needs to assess the activities and processes that are related to innovation, such as; technology transfer processes, collaborative innovation activities, consultancies and academic spinoffs.

For this study a new APMS is applied according to the needs of universities by using a synthetic data based on an engineering department's KPIs. APMS scores are calculated based on the cumulative metric of all research and innovation activities and, weighted according to the needs and considerations of the university. The results of this study show that many of those academicians who have great performance in publications and academic research do not necessarily have high-level performance in innovative activities. In fact the results show that those who had high points in some measurements have very low performance in others. For the management point of view, it may be more effective to position academicians for different roles and assess their performance accordingly as innovation-targeted, teaching-targeted and research-targeted academicians.
\end{abstract}




\section{Introduction and Background of the Study}

The changing roles of universities from being heavily based on fundamental research to applied research also led to a necessity for different internal and external systems to have a better adoption in the innovation systems. Universities' functions are expanding from their traditional roles such as; education, research and publications to also innovation related aspects. New funding mechanisms encourage academicians to take part in collaborative research with different actors and also commercialize their ideas in the industry. Various studies [1, 2] make clear that academic actors with funding undertake more applied research nowadays and that innovation related activities within academia are a more of a focus point.

Currently, there are more "entrepreneurial universities" than before. The studies show that there is a rapid change in this new era where academicians are taking a greater role in innovative activities and are motivated to be involved in entrepreneurial activities. However, this is also considered to be dangerous as excessive applied research results at the expense of fundamental research [3]. Accordingly, academic performance may need to be balanced between well-known duties and innovation related roles.

The widely accepted triple helix model shows changing and overlapping roles of academic, industrial and governmental actors [4]. The management of academic organizations also favors those individuals who assist in the goals of universities with regards to TTO processes, innovation and collaborative research with external partners. The main motivations of academic organizations to have an active role in innovation systems are: 1) to generate more funds for research, 2) to have a better position in rankings and 3) to be an incubator for academic spin-off companies.

Academic organizations are currently expending some of their energy on commercialization related activities due to the various benefits of interaction with industrial actors, such as increased levels of funding. Accordingly, the numbers of technology transfer departments and their activities are rapidly increasing. Industrial actors heavily invest in fundamental science, government actors are highly aware of the positive returns on innovation so they adjust their policies and their involvement accordingly to encourage universities to engage in industryoriented research. 
Many universities are currently trying to establish the right mechanism so that they can produce industrial externalities and technology transfer related outcomes. There are various external factors to motivate academicians to engage in innovative activities such as science and technology policies, funding mechanisms and innovation networks. Financial gain for some academicians to get involved in industrial-oriented research can be an extrinsic motivation but the goals of their organization may not be met successfully and continually by just focusing on extrinsic motivation factors. Accordingly, apart from external motivating factors, an internal system is required to encourage academicians to engage in innovation processes.

Various studies show that just focusing on extrinsic motivating factors is not a solution to increase performance but that intrinsic motivation factors should also be included in the performance management systems by balancing both factors [5-7]. Some studies show that extrinsic factors have positive effect on intrinsic factors but it differs based on the group of people (i.e. students or employees) [8, 9]. Especially for academia, intrinsic factors appear to be more effective as performance triggering elements. Some authors explained that a combination of both intrinsic and extrinsic factors lead to a better performance in organizations. [10]. In general, it is well known that every individual would not be motivated by same factors so that performance management systems need to be as comprehensive as possible to cover various expectations of employees. Moreover, it can be assumed that every academician would be competent in different areas such as writing publications, teaching and research projects.

This paper aims to explain how academic performance management may assess the academicians' involvement in the changing roles of universities in innovation systems. Academic performance is required to be measured based on the new roles of universities and it needs to be managed according to organizational culture in such a way that would lead to better performance. Academicians should be encouraged to adapt to new industry oriented research through organizational and national goals for the benefit of national performance. For this, performance measurement systems and motivational factors are examined in the following section. 


\section{Literature Review}

A performance measurement system means the application of a multi-dimensional set of performance measures referred to as key performance indicators (KPIs). KPIs can consist of both financial and non-financial measures. Based on these measurements, achievements of employees are assessed and the results are used for motivational purposes (both intrinsic and extrinsic) and for planning purposes by means of strategic management activities for current conditions and the future [11].

Performance measurement systems are not just popular amongst industrial organizations, academic management also uses KPIs to assess their employee's performance. Statistics show that $30-60 \%$ of large US firms have adopted the balanced scorecard [12]. In performance measurement systems, there are various elements that need to be decided on such as duration of the measurement, indicators to be measured, measurement methods and performance targets [13].

There are different performance measurement systems based on statistical methods and their usage. The most popular performance measurement systems are Balanced Scorecard [14], Performance Prism [15] and the EFQM Business Excellence Model [16]. Balanced Scorecard (BS) fulfills three functions that are: the measurement system, the system of strategic management and the tool for communication. The BS system focuses on four strategic elements that are: financial, internal processes, customer and, learning and growth; all of these need to be balanced. Here balance means the equability between short-term and long-term goals, required inputs and outputs, internal and external performance factors, and financial and non-financial indicators [17]. All these performance measurement systems need to be adjusted according to the needs of the organization itself and there is no a single superior performance measurement system that can be applied to all. For example, if one crucial step in a performance measurement system is to do benchmarking then EFQM would be a more suitable model for the management.

In academia, there are some academic performance measurement systems (APMS) but current APMS are not adjusted according to the changing roles of academia and may require to be renewed for the current needs of innovation systems. Performance measurement systems in general include: 1) individual measures, 2) a set of measures that combine to assess the performance as a whole and 3) a system to collect, analyze, interpret and disseminate the data [18]. Many APMS focus on KPIs such as: publications, research projects and patents [19, 20]. 
However, the new APMS need to assess the activities and processes that are related to the innovation. Some of these could be linked to technology transfer processes, collaborative innovation activities, consultancies and academic spin-offs. In the methodology section below, an equation is provided to cover all the necessities of the contemporary roles of academic organizations.

\section{Methodology}

For this study a new APMS is applied according to the needs of universities by using a synthetic data based on an engineering department's KPIs. The engineering faculty is selected as a case study because these types of academic units are closer to innovative activities. APMS scores are calculated based on the cumulative metric of all research and innovation activities and weighted according to the needs and considerations of the university. This can be adjusted according to strategic plans of another research organization. For example, if patents are rewarded more compared to other features (i.e. publications) then the weight for granting patents should be increased. Also, the weighting system can be adjusted to value quality against the quantity of work by giving more weight to impact factors, citations and technology transfer metrics.

According to the study of [13], there are different types of performance measurement design. In terms of different procedures, the 'needs led' approach is a top-down method, the 'audit led' procedure is a bottom-up method and the 'model led' procedure is a framework where, for example, the ECOGRAI model is followed. In this study a top-down method is employed based on the needs of the university.

In terms of the performance measurement approach, there are consultant led approaches that is completed by some individuals that are outside of the management system and facilitator led where management team together in facilitated workshops. This study followed a facilitator led approach by challenging existing measures and transform strategy into action.

There are external and internal factors to encourage organizations to pursue innovative results. Science and technology policies, funding mechanisms and innovation networks are some of the external factors that drive academia into industry-oriented research. Apart from external motivating factors, an internal system is required to encourage academicians to engage in innovation processes. 
In this study, Equation 1 is used to calculate the APMS score. Innovation related factors are added to previously measured academic roles as discussed in the literature review section. To give higher value to an academic organization engage in innovative activities, patents, projects, collaborative innovation, technology transfer, consultancies and spin-offs need to have higher weights compared to other terms:

$A P M S$ score $=W F_{p} \times P+W F_{b} \times B+W F_{b c} \times B C+W F_{c p} \times C P+W F_{c t} \times C T+W F_{p t} \times P T+$ $W F_{p r} \times P R+W F_{t} \times T+W F_{s S} \times S S+W F_{c i} \times C I+W F_{t t} \times T T+W F_{c o} \times C O+W F_{s o} \times S O$ (1)

The meaning of each term used in the above equation is as follows:

$W F$ - weighting factor, $P$ - journal paper, $B$ - Book, $B C$ - book chapter, $C P$ - conference paper, $C T$ - citations, $P T$ - patents, $P R$ - projects, $T$ - teachings, $S S$ - student satisfaction surveys, $C I$ - collaborative innovation, $T T$ - technology transfer, $C O$ - consultancies, $S O$ - spin-offs.

For all types of publications, points are calculated as given in Equation 2 for journal publications as an example by taking into account the number of authors. Publications with single author are accepted as 1 point for journal papers, 2 points for book publications, 0.4 points for international conference papers, 0.25 points for national conference papers and 0.25 points for book chapters. This academic evaluation report covers activities of each academic staff for 2013, 2014 and 2015. Other terms are also formulated as shown for the publication case. Due to the space limitation of submission, other equations are not presented in this paper.

$$
P=\frac{1}{T_{p}} \times \sum_{k=1}^{N p}\left(\begin{array}{c}
\text { single author } ; 1 \\
\text { two authors } ; 0.8 \\
\text { more than two authors } ; \frac{1.8}{n a}
\end{array}\right)
$$

where terms are as described below; $P$ - journal paper points, $T p$ - time period, $k$ - journal paper index, $N p$ - number of journal papers over the time period, $\mathrm{Na}$ - number of authors 


\section{Results and Discussion}

Results for 20 randomly selected academicians from a total of 68 are represented in Table 1. Academic activities are listed in the first five columns of the table, and the next six columns lists innovation related activities. Each measurement is completed based on its particular equation as shown for Equation 2. The results below are based on three years of activity of the academicians. The academic score is calculated based on the average value of papers, conferences, books, books chapters and citations. The innovation score is calculated based on patents, projects, consultancies, collaborative innovation, technology transfers and spin-offs. A scatter plot of innovation versus academic score given in Figure 1 for the 68 academicians included in this study. Academic score (AS) and innovation score (IS) are all derived from other scores such as journal papers, conferences and book chapters. These scores are used in the following sections to see if there is any correlation between various scores.

Table 1: APMS points and corresponding academic and innovation scores for a subset of 20 academicians.

\begin{tabular}{|c|c|c|c|c|c|c|c|c|c|c|c|c|c|}
\hline 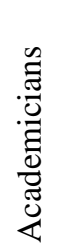 & 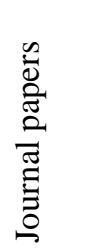 & 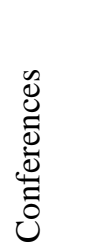 & 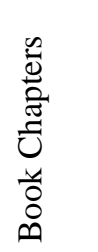 & 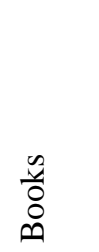 & & 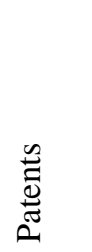 & $\begin{array}{l}\frac{\tilde{U}}{0} \\
\frac{\mathscr{d}}{0} \\
\end{array}$ & 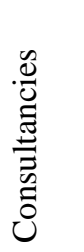 & 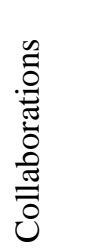 & $\stackrel{n}{H}$ & లో & 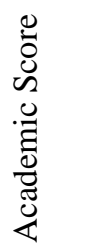 & 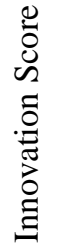 \\
\hline A1 & 2.06 & 0.37 & 0.00 & 0.00 & 0.36 & 0.00 & 0.11 & 0.00 & 0.05 & 0 & 0 & 0.46 & 0.03 \\
\hline A2 & 0.61 & 0.04 & 0.00 & 0.00 & 0.16 & 0.00 & 0.11 & 0.00 & 0.05 & 0 & 0 & 0.13 & 0.03 \\
\hline A3 & 1.40 & 0.00 & 0.00 & 0.00 & 0.17 & 0.00 & 0.52 & 0.37 & 0.44 & 0 & 0 & 0.26 & 0.22 \\
\hline A4 & 0.94 & 0.48 & 0.00 & 0.00 & 0.24 & 0.00 & 0.11 & 0.00 & 0.05 & 0 & 0 & 0.28 & 0.03 \\
\hline A5 & 0.00 & 0.00 & 0.00 & 0.00 & 0.07 & 0.00 & 0.00 & 0.00 & 0.00 & 0 & 0 & 0.01 & 0.00 \\
\hline A6 & 0.69 & 0.00 & 0.00 & 0.00 & 0.00 & 0.00 & 0.00 & 0.00 & 0.00 & 0 & 0 & 0.11 & 0.00 \\
\hline A7 & 0.62 & 0.14 & 0.00 & 0.00 & 0.19 & 0.00 & 0.11 & 0.00 & 0.05 & 0 & 0 & 0.16 & 0.03 \\
\hline A8 & 0.00 & 0.00 & 0.00 & 0.00 & 0.14 & 0.00 & 0.00 & 0.00 & 0.00 & 0 & 0 & 0.02 & 0.00 \\
\hline A9 & 0.34 & 0.00 & 0.00 & 0.00 & 0.44 & 0.00 & 0.21 & 0.00 & 0.11 & 0 & 0 & 0.13 & 0.05 \\
\hline A10 & 0.39 & 0.08 & 0.09 & 0.00 & 0.13 & 0.00 & 0.11 & 0.00 & 0.05 & 0 & 0 & 0.11 & 0.03 \\
\hline A11 & 0.15 & 0.00 & 0.00 & 0.00 & 0.06 & 0.00 & 0.11 & 0.00 & 0.05 & 0 & 0 & 0.04 & 0.03 \\
\hline A12 & 0.54 & 0.24 & 0.00 & 0.00 & 0.97 & 0.00 & 0.00 & 0.00 & 0.00 & 0 & 0 & 0.29 & 0.00 \\
\hline A13 & 3.86 & 0.00 & 0.00 & 0.00 & 1.59 & 0.00 & 0.00 & 0.00 & 0.00 & 0 & 0 & 0.91 & 0.00 \\
\hline A14 & 0.65 & 0.39 & 0.17 & 0.00 & 0.86 & 0.00 & 0.49 & 0.97 & 0.73 & 1 & 0 & 0.34 & 0.37 \\
\hline A15 & 0.19 & 0.00 & 0.00 & 0.00 & 0.07 & 0.00 & 0.11 & 0.00 & 0.05 & 0 & 0 & 0.04 & 0.03 \\
\hline A16 & 0.60 & 0.33 & 0.05 & 0.00 & 0.66 & 0.00 & 0.00 & 0.00 & 0.00 & 0 & 0 & 0.27 & 0.00 \\
\hline A17 & 0.52 & 0.00 & 0.00 & 0.00 & 0.03 & 0.00 & 0.00 & 1.08 & 0.54 & 1 & 0 & 0.09 & 0.27 \\
\hline A18 & 1.72 & 1.30 & 0.09 & 0.00 & 0.76 & 0.00 & 0.39 & 1.03 & 0.71 & 1 & 0 & 0.64 & 0.35 \\
\hline
\end{tabular}




$\begin{array}{llllllllllllll}\text { A19 } & 0.45 & 0.27 & 0.09 & 0.00 & 1.42 & 0.00 & 0.11 & 0.09 & 0.10 & 0 & 0 & 0.37 & 0.05 \\ \text { A20 } & 5.62 & 0.45 & 0.00 & 0.00 & 1.86 & 0.00 & 0.11 & 0.00 & 0.05 & 0 & 0 & 1.32 & 0.03\end{array}$

As shown in Table 2, correlation calculations for various combinations are performed to see if any academic work has an impact on innovation performance of the academicians. The results show that there is no significant relationship between any conventional academic activity and the innovation score. That is if academicians perform better in activities such as publishing papers, attending conferences and having highly cited papers, it does not mean that they will have a better performance in innovative activities as well. A notable finding is that those academicians who have high citations, show some correlation (22\%) with their innovation performance. Thus, it may mean that quality vs. quantity in papers affect the innovative outputs. As expected, there was a significant relationship between number of papers published and number of citations. This comparison is done to check if the calculations were followed properly. Those academicians who provide consultancy to industrial actors show greater performance in research projects and also collaborative innovation activities.

Table 2: Correlation coefficients for academic and innovation related activities

\begin{tabular}{lc} 
Calculated Units & The Correlation Coefficient \\
\hline AS vs. IS & 0.10 \\
Papers vs. IS & 0.00 \\
Conferences vs. IS & 0.05 \\
Citations vs. IS & 0.22 \\
Papers vs. Consultancies & 0.09 \\
Papers vs. Conferences & 0.14 \\
Papers vs. Citations & 0.51 \\
Patents vs. Projects & 0.22 \\
Patents vs. Consultancies & 0.01 \\
Projects vs. Consultancies & 0.43 \\
Consultancies vs. Collaborations & 0.86
\end{tabular}

AS - Academic Score, IS - Innovation Score 


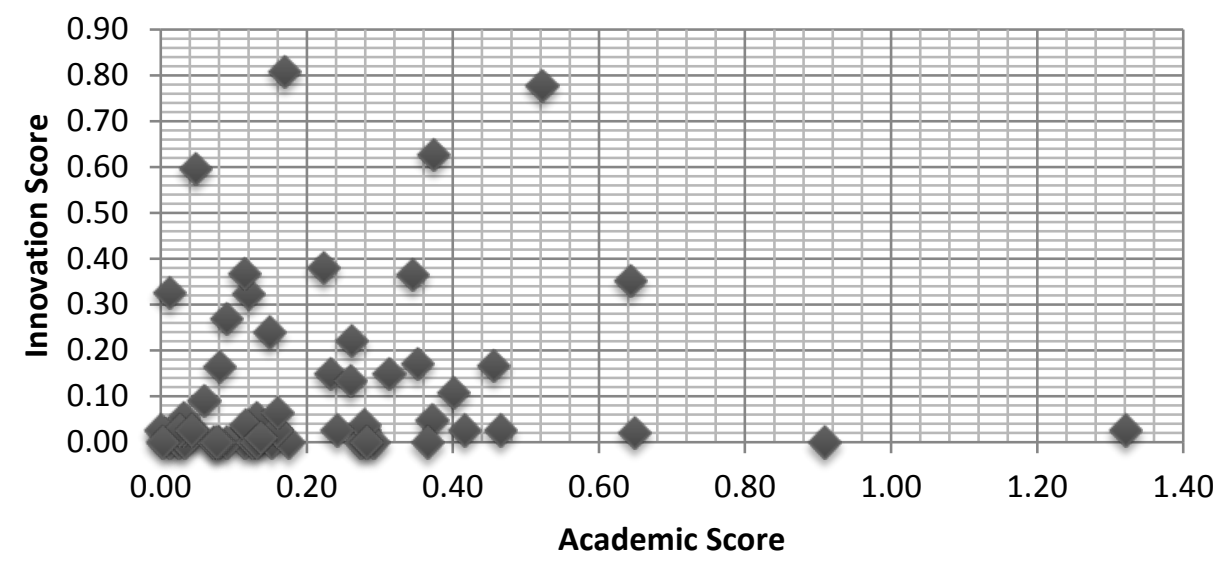

Figure 1: The relationship between innovation and academic score

\section{Conclusions}

The results of this study showed that many of those academicians who have great performance in publications and academic research does not necessarily have high-level performance in innovative activities. In fact, the results showed that majority of those who had high points in academic performance had low performance in the innovation performance or vice versa. There were also very rare individuals who had high points from both side of performances that are calculated. This may indicate that it is not easy to handle academicians both side of duties and perform well.

With respect to management, the results of the study indicate that it may be more effective to position academicians for different areas and assess their performance accordingly as innovationtargeted, teaching-targeted and research-targeted academicians. Here, research-targeted academicians can be those that are mainly focusing on publications and fundamental research. There can be teaching-targeted academicians (not teaching fellows) where their performance measurements are weighted for teaching skills and number of lectures. Innovation-targeted lecturers can be those lecturers focusing on collaborative, industrial or applied research and technology transfer related elements.

This study can be a benefit to various organizations such as universities who would like to assess their academicians, governmental bodies who are aiming to rank universities and firms who are planning to collaborate with researchers from universities. Although those universities who 
follow such a system may prefer keeping their results to themselves, governmental bodies may perform such analysis to rank academicians by region or by field. This type of performance measurement method can be useful for firms if it is made available publicly for other private organizations to assess whom to collaborate with. 


\section{References}

[1] Gulbrandsen, M. and J.C. Smeby (2005). "Industry Funding and University Professors' Research Performance”, Research Policy 34, 932-950.

[2] Glenna, L.L., R. Welsh, D. Ervin, W.B. Lacy and D. Biscotti (2011). "Commercial Science, Scientists' Values, and University Biotechnology Research Agendas”, Research Policy 40, 957968.

[3] Van Looy B., M. Ramga, J. Callaert, K. Debackere, E. Zimmermann (2004). Combining entrepreneurial and scientific performance in academia: towards a compounded and reciprocal Matthew-effect? Research Policy, 33. pp. 425-441

[4] Etzkowitz, H., Leydesdorff, L. (2000). The dynamics of innovation: from National Systems and "Mode 2" to a Triple Helix of university-industry-government relations. Research Policy 29, $109-123$.

[5] Amabile, T. M. (1993). Motivational synergy: Toward new conceptualizations of intrinsic and extrinsic motivation in the workplace. Human resource management review, 3(3), 185-201.

[6] Harackiewicz, J. M. (2000). Intrinsic and extrinsic motivation: The search for optimal motivation and performance. Academic Press.

[7] Frey, B. S., \& Osterloh, M. (Eds.). (2001). Successful management by motivation: Balancing intrinsic and extrinsic incentives. Springer Science \& Business Media.

[8] Deci, E. L., Koestner, R., \& Ryan, R. M. (1999). A meta-analytic review of experiments examining the effects of extrinsic rewards on intrinsic motivation. Psychological bulletin, 125(6), 627.

[9] Wiersma, U. J. (1992). The effects of extrinsic rewards in intrinsic motivation: A metaanalysis. Journal of Occupational and Organizational Psychology, 65(2), 101-114.

[10] Saracli, S., Keskinturk, T., Cicek, M. And Gazeloglu, C., 2014. "Examining The Effects Of Organizational Commitment On Intrinsic And Extrinsic Motivation Via Structural Equation Modelling: Turkish Academicians Case." Fen Bilimleri Dergisi 2.2 (2014).

[11] Berkeley, U. C. (2010). Guide to Managing Human Resources.

[12] Neely, A. (2008). Does the balance scorecard work: an empirical investigation.

[13] Bourne, M., Neely, A., Mills, J., \& Platts, K. (2003). Implementing performance measurement systems: a literature review. International Journal of Business Performance Management, 5(1), 1-24. 
[14] Kaplan, Robert S. and Norton, David P; (1996)"Using the Balanced Scorecard as a Strategic Management System", Harvard Business Review.

[15] Neely, A., Adams, C. and Kennerley, M. (2002), The Performance Prism: The Scorecard for Measuring and Managing Stakeholder Relationships, Financial Times/Prentice Hall, London

[16] EFQM (2003), EFQM Homepage, available at: www.efqm.org.

[17] Striteska, M., \& Spickova, M. (2012). Review and comparison of performance measurement systems. Journal of Organizational Management Studies, 2012, 1.

[18] Neely, A. (2007). Business Performance Measurement: unifying theory and integrating practice. Cambridge University Press.

[19] Al-Turki, U.,Duffuaa, S. (2003). Performance measures for academic departments. International Journal of Educational Management, 17(7), 330-338.

[20] Masron, T. A., Ahmad, Z., Rahim, N. B. (2012). Key performance indicators vs key intangible performance among academic staff: A case study of a public university in Malaysia. Procedia-Social and Behavioral Sciences, 56, 494-503. 